\title{
Demonstration of Evaporation Inhibition with Floating Polystyrene Board and Its Motion Response
}

\author{
Haibo Jiang ${ }^{*}$ and Yan Tian
}

School of Water \& Architectural Engineering, Shihezi University, Shihezi, Xinjiang, 832000, P.R. China

\begin{abstract}
Plain reservoirs in arid areas usually have a shallow water depth, a large surface area, and severe evaporative water-loss. To lessen the water loss, a polystyrene board coverage technique was used. This paper represents a demonstrative application study of the polystyrene board coverage technique in the Daquangou Plain Reservoir in the city of Shihezi, Xinjiang. Six different polystyrene board structures were created and tested to measure the wind wave resistance level, damage type, and reason for the damage. To study the motion of the floating polystyrene board in waves, this paper applied the kinematic theory for rigid bodies and utilized the Newton's Second Law to develop the coupling kinematic equation for the polystyrene board. We also used a modified sectioning method to calculate the added mass of the floating polystyrene board, fluid damping, and static water restoring force. The heave and pitch motion response of the floating polystyrene board was analyzed and determined to be periodic. The connection and fix strategy for the polystyrene board structures could resist the effect of level-6 wind waves, which served the purpose of inhibiting the evaporation in the plain reservoir.
\end{abstract}

Keyword: Floating polystyrene board, plain reservoir, polystyrene board coverage technique, motion response, wave load.

\section{INTRODUCTION}

As the largest inland arid area in China, Xinjiang suffers several bottle-neck problems in water resources technology development, including insufficient water resource control, difficulties overcoming flood and drought, poor water resource development and distribution, low efficiency of utilization in agricultural irrigation, and severe secondary salinization of soil [1]. To conquer the serious shortage of water, a variety of conservation methods have been used in the arid areas of the northwest [2-4]. Although agricultural water-conservation projects have made excellent achievements, water-conservation from the source has not been well recognized. Particularly, minimizing the waterloss due to the evaporation from reservoir has not been the focus. In arid and semi-arid areas, there is a lot of evaporation, and consequently, major water loss. For example, in Xinjiang, the mean annual evaporation is about $2463.6 \mathrm{~mm}$ and the multi-year average precipitation is $147 \mathrm{~mm}$. Xinjiang has built 489 reservoirs and the total storage capacity is 8.378 billion $\mathrm{m}^{3}$. According to existing research [5], the Xinjiang Plain Reservoir has an annual evaporation of $26.1 \times 108 \mathrm{~m}^{3}$. The water-loss due to evaporation is greater than $40 \%$ of the total storage capacity. This evaporation from the water surface significantly reduces the utilization and efficiency of the reservoir. Tremendous water resources would be saved if the evaporation could be effectively inhibited.

To date, little research about the inhibition of reservoir surface evaporation in arid and semiarid areas has been

*Address correspondence to this author at the School of Water \& Architectural Engineering, Shihezi University, Shihezi, Xinjiang, 832000, P.R. China; Tel: +86 18209056355; E-mail: klaud_123@163.com conducted [6-12]. Theory and research achievements on the inhibition methods of evaporation for plain reservoir in inland arid and semiarid area have not been well developed. Moreover, no research has been carried out to explore several particular aspects. Therefore, many questions remain. For instance, it is yet to be determined whether the polystyrene board coverage technique and monolayer technology can be extensively used for plain reservoir and how to use these technologies? What is the wind wave resistance property of polystyrene board and monolayer structures? How do the different coverage techniques adapt to the climate change in arid area? All these questions are intriguing enough to be further investigated. Therefore, the inhibition of reservoir evaporation has broad research potential. Effectively inhibiting the evaporation from the reservoir water surface not only will provide significant economic, ecological, and societal benefits, but also advances the sustainable development of the western area of China. It is meaningful and important to carry out the research on the inhibition of evaporation of reservoir in arid and semiarid area.

According to the aforementioned characteristics of plain reservoirs in arid areas, this paper investigates the application of the polystyrene board coverage for plain reservoirs in arid areas. We conducted demonstrative research of the polystyrene board coverage technique in the Daquangou Plain Reservoir in Xinjiang. The anti-wind wave effect of the structure was investigated with different board densities and strategies, and methods of fix and connection. This paper also examined the damage effect of wind waves to the polystyrene board structure. To study the motion response of the floating polystyrene board in the waves, we applied the theory of rigid body kinematics and used Newton's Second Law to develop a coupling equation for 
floating bodies with six degrees of freedom. This study utilized a modified sectioning method to calculate the added mass of the floating polystyrene board in regular waves, added damping and static water restoring forces. Taking two modes of horizontal and vertical motions as the examples, this study calculated the wave load and motion response in two modes of motion for the floating body in regular waves. The motion response characteristics were also analyzed.

\section{DEMONSTRATIVE STUDY OF POLYSTYRENE BOARD COVERAGE TECHNIQUE IN PLAIN RESERVOIR}

The demonstration area for the polystyrene board inhibition of evaporation was in the Daquangou Reservoir in Shihezi, Xinjiang. This reservoir is a mid-size, diversioninjection type plain reservoir in the Manas River Basin. The dam of the reservoir is a rolling-type, uniform earth dam. The altitude of the dam crest is $391.90 \mathrm{~m}$. The maximum dam height is $12.66 \mathrm{~m}$. The storage capacity is 40 million $\mathrm{m}^{3}$, and the annual regulating water content is about 0.1 billion $\mathrm{m}^{3}$. The area of the reservoir has a continental climate. The multi-year mean temperature is $6.6^{\circ} \mathrm{C}$. The multi-year mean precipitation is $198.8 \mathrm{~mm}$ and the multi-year mean evaporation is $1514.9 \mathrm{~mm}$. The multi-year mean maximum wind speed is $20 \mathrm{~m} / \mathrm{s}$. The annual averaged water surface area in the reservoir is $10 \mathrm{~km}^{2}$ (Table $\mathbf{1}$ ).

According to the field measurement data, under the effect of gravity, a body of water has a periodic motion under the disturbance of wind. When the wind speed is relatively small, wavelets can be generated on a calm surface. With an increase in wind speed and continuous action on the water surface, wavelength and wave height increase gradually and gravity waves are formed. Energy is then transferred into the body of water itself, inducing a series of waves with different wavelengths and speeds. These waves overlap and interfere in different directions, forming irregular and nonuniform waves. Since these waves are essentially random, it is impossible to describe their motion with any known methods. In theory, a characteristic wave can be statistically used to represent the superposition of different periods, wave heights, and wave phases.

From the in situ demonstration, three different strategies for fix and connection and two different polystyrene board densities were used. The measurement results are shown in Table 1. The relationship between the flexural strength of the board and the density is shown in Fig. (1).

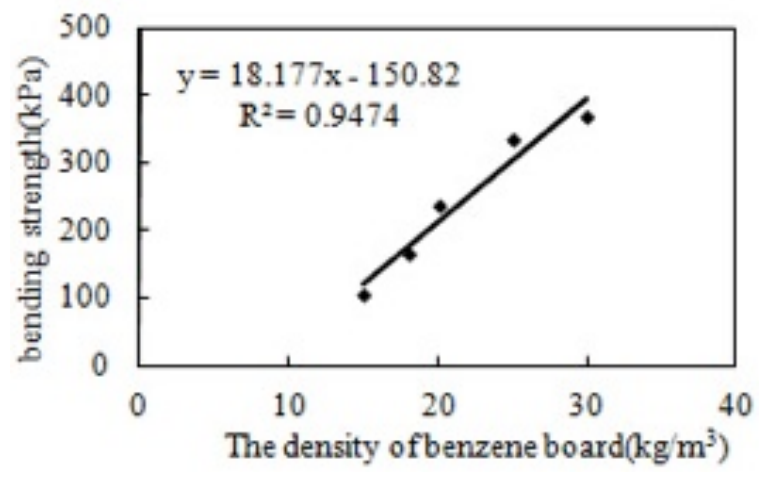

Fig. (1). Relationship between bending strength and density of the polystyrene board.

Though long-term observation, the different connection and fix strategies had a large impact on the boards' overall wave-resistance ability. With multiple tests, the fifth and sixth connection and fix strategies were confirmed: the long side of the board was clamped with wooden slats and nails, referred to as fixing the boards. On the long side, the board and the wooden slats were fastened with a high-strength cord, connected to the reinforced net underneath. The neighboring boards were separated with a predetermined position to reduce the constraint. This protected the boards from collision damage, as shown in Fig. (2).

The connection and fix strategy shown in Fig. (2), can resist level-6 wind and waves. The only limitation is keeping the board coverage away from the bank of the reservoir. The polystyrene board can touch the bank slope. Under the effect

Table 1. In situ demonstrative experiment summary.

\begin{tabular}{|c|c|c|c|}
\hline $\begin{array}{c}\text { Experiment } \\
\text { Strategies }\end{array}$ & Connection and Fix Strategies; Experimental Area & $\begin{array}{l}\text { Resistance to Wind } \\
\text { Level and Speed }\end{array}$ & Damage Reason \\
\hline 1 & $\begin{array}{l}1.5 \mathrm{~m} \times 1.23 \mathrm{~m} \text { polystyrene board in series. The thickness of board is } 3 \mathrm{~cm} \text {, board density } \\
\text { is } 18 \mathrm{~kg} / \mathrm{m}^{3} \text {, net coverage on one side, with coverage area of } 400 \mathrm{~m}^{2}\end{array}$ & $\begin{array}{c}\text { Under level } 4 \\
3.4-5.4 \mathrm{~m} / \mathrm{s}\end{array}$ & $\begin{array}{c}\text { Disjointed } \\
\text { Board broken }\end{array}$ \\
\hline 2 & $\begin{array}{l}1.5 \mathrm{~m} \times 1.23 \mathrm{~m} \text { polystyrene board in parallel. The thickness of board is } 5 \mathrm{~cm} \text {, board } \\
\text { density is } 20 \mathrm{~kg} / \mathrm{m}^{3} \text {, net coverage on one side, with coverage area of } 400 \mathrm{~m}^{2}\end{array}$ & $\begin{array}{c}\text { Level } 4 \\
5.5-7.9 \mathrm{~m} / \mathrm{s}\end{array}$ & $\begin{array}{c}\text { Connection joint } \\
\text { broken, board damage }\end{array}$ \\
\hline 4 & $\begin{array}{c}1.5 \mathrm{~m} \times 1.23 \mathrm{~m} \text { polystyrene board in parallel. The thickness of board is } 5 \mathrm{~cm} \text {. board } \\
\text { density is } 20 \mathrm{~kg} / \mathrm{m}^{3} \text {. reinforced net coverage on one side, polished, with coverage area } \\
\text { of } 400 \mathrm{~m}^{2}\end{array}$ & $\begin{array}{l}\text { Level } 5 \\
8.0-10.7 \mathrm{~m} / \mathrm{s}\end{array}$ & $\begin{array}{l}\text { Board broken } \\
\text { Damage }\end{array}$ \\
\hline 5 & $\begin{array}{c}1.5 \mathrm{~m} \times 1.23 \mathrm{~m} \text { polystyrene board in series, The thickness of board is } 3 \mathrm{~cm} \text {, board density } \\
\text { is } 18 \mathrm{~kg} / \mathrm{m}^{3} \text {, reinforced net coverage on two sides, polished, with coverage area of } \\
400 \mathrm{~m}^{2}\end{array}$ & $\begin{array}{l}\text { Level } 6 \\
10.8-13.8 \mathrm{~m} / \mathrm{s}\end{array}$ & No damage \\
\hline
\end{tabular}


of wind wave, the waves can superimpose onto the previous waves close to the bank, which increases the interacting force between the board and the bank slope, resulting in damage of the boards. When the polystyrene boards were not in contact with the bank slope or far away from it, they would freely float with oscillation of the wind and waves. Therefore, relatively weak friction among them would not affect the stability of the polystyrene board coverage structure.

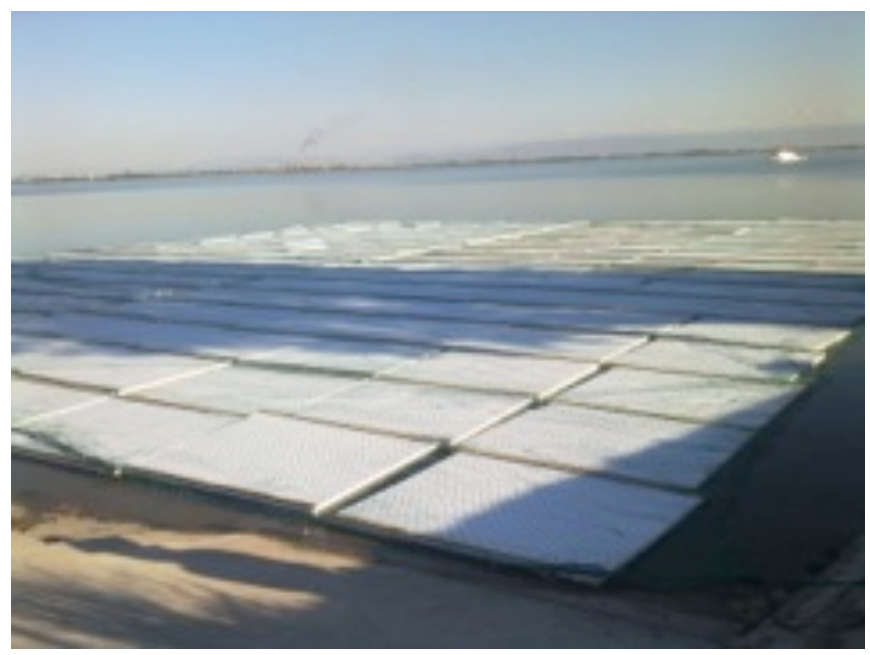

Fig. (2). Connection and fix strategy.

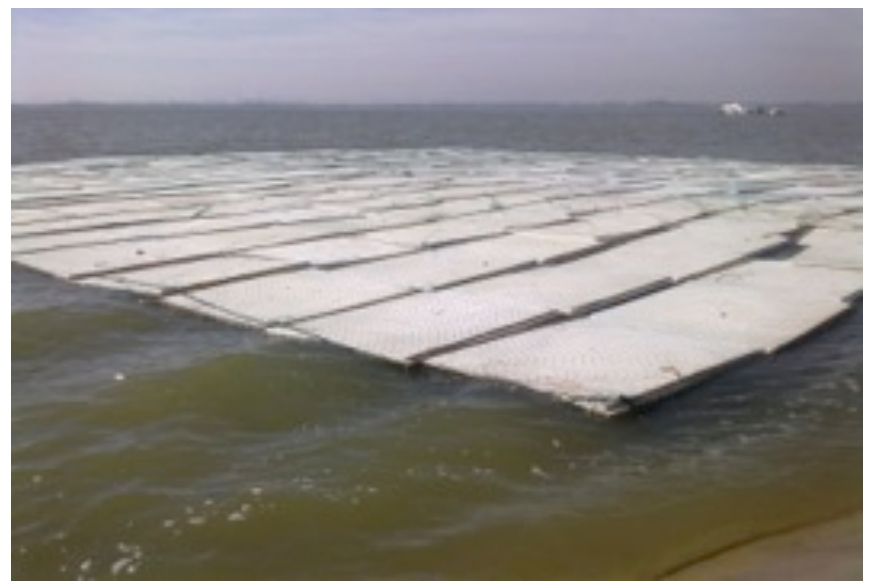

Fig. (3). Motion behavior of the polystyrene board coverage structure under level-6 wind wave.

Fig. (3) shows the motion response scenario of the polystyrene board coverage structure in a level- 6 wind wave environment. In the water area far away from the bank, the polystyrene board coverage structure was able to maintain stability, following the horizontal and vertical motion of second order wave force.

\section{MOTION RESPONSE ANALYSIS OF FLOATING POLYSTYRENE BOARD IN WIND WAVES}

To analyze the Motion Response Condition of the floating polystyrene board in waves, this study applied Newton's Second Law to establish the coupling kinematic equation. The modified sectioning method was used to calculate the kinematic parameters, including added mass of the floating polystyrene board, added damping, and static water restoring force. The motion response of the floating polystyrene in waves were also analyzed [13-15].

According to the demonstrative study of the polystyrene board coverage structure in a plain reservoir, the real situation of the board motion in waves was complex. To simplify the analysis and discussion, three assumptions were made here:

When the motion and force of the polystyrene board in waves is analyzed, the floating polystyrene boards are rigid bodies. Their elastic deformations are ignored.

The wave force acting on the floating polystyrene boards is a deep-water micro-amplitude wave. The effect of shallow water and nonlinearity on the motion response is ignored.

The floating polystyrene boards oscillate gently in regular waves, thus simplifying the motion and forcing the problem of the floating polystyrene boards in wave to be a linear problem.

The motion of floating polystyrene boards in waves is based on the idea of rigid body motion in an infinite and fluid region. Under the coordinate system $O-X Y Z$, the floating body kinematic equation can be deduced from the Newton's Second Law:

$A \ddot{X}_{i}=F_{i}$

In equation, $\ddot{X}_{i}$ is the displacement along the axis when $i=1,2,3$. The total force on the floating body is:

$F_{i}=\int_{l}\left(F_{1}+F_{2}+F_{3}\right) d x$

While $i=4,5,6, \ddot{X}_{i}$ is the rotation displacement with respect to the axis. The total moment of floating body is:

$F_{i}=-\int_{l}\left(F_{1}+F_{2}+F_{3}\right) x d x$

$F_{1}$ is hydrostatic force, $F_{2}$ is the damping force of the fluid and $F_{3}$ is the added inertia force. $A$ is the generalized mass matrix of the floating body, which can be described as:

$$
A=\left\{\begin{array}{cccccc}
m & 0 & 0 & 0 & m y_{c} & 0 \\
0 & m & m & -m y_{c} & 0 & m x_{c} \\
0 & 0 & m & 0 & -m x_{c} & 0 \\
0 & -m y_{c} & 0 & I_{4} & 0 & -I_{5} \\
m y_{c} & 0 & -m x_{c} & 0 & I_{5} & 0 \\
0 & m x_{c} & 0 & -I_{5} & 0 & I_{6}
\end{array}\right\}
$$

In equation (4), $m$ is the mass of the floating body, $x_{c}$ is the vertical coordinate of the buoyancy center of the floating body, and $I_{5}$ is the moment of inertia of the floating body with respect to $y$-axis.

\section{CALCUlation OF WAVE FORCE AND MOMENT OF THE FLOATING BODY}

Hydrostatic force is the static buoyancy of the floating body in waves. Due to the various drafts, the static buoyancy for unit length can be calculated: 
$T_{1}=-\rho g b \omega_{r}$

In equation (5), $b$ is the width of the floating body. $\omega_{r}$ is the relative displacement of the floating body with respect to the water surface. $\omega_{r}=(z-x \beta-\bar{\zeta}), \bar{\zeta}$ is Smith modified coefficient [16].

The damping force acting on the floating body is:

$T_{2}=-N \dot{\omega}_{r} d x$

In equation (6),

$N$ is the damping coefficient. $\dot{\omega}_{r}$ is the velocity of the floating body with respect to the wave surface, which can be calculated as $\dot{\omega}_{r}=\dot{z}-\beta x+\beta v-\tilde{\zeta}$.

The momentum of the floating body can be calculated from the Momentum Theorem:

$P=m \dot{\omega}_{r}$

In equation (7),

$m$ is the added mass of the section, which could calculate the added inertia of the floating body. The added mass in the vertical section of the floating body does not change, so the above equation can be written as:

$p=-\frac{d}{d x}\left(m \dot{\omega}_{r}\right)=-m(\ddot{z}-\ddot{\beta} x+2 \beta v-\ddot{\tilde{\zeta}})$

After obtaining the wave force and wave moment $F$ in the kinematic equation of the floating body, they can be substituted into the floating body kinematic equation (1). Rearranging the equation yields the detailed expression of the linear kinematic equation of the floating polystyrene boards: Table 2 .

$\sum\left[-\omega^{2}{ }_{e}\left(m_{i j}+a_{i j}\right)+i \omega_{e} b_{i j}+c_{i j}\right] x_{j}=f_{j}$

In equation (9), $\omega_{e}$ is encounter frequency and $f_{j}$ is generalized wave force.

Under the effect of second order wave force, the motion response of the floating polystyrene boards corresponded to the coupling motion of six degrees of freedom.

\section{CASE STUDY AND CALCULATION}

\subsection{Result}

According to the demonstrative experiment on the application of polystyrene boards coverage technique at Daquangou reservoir, we investigated the motion response of the polystyrene board structure and the damage type under wind waves at different levels. The average water depth in the Daquangou Plain Reservoir is $7.9 \mathrm{~m}$. The maximum wind speed is $20 \mathrm{~m} / \mathrm{s}$. The density of the primary lightweight floating board is $20 \mathrm{~kg} / \mathrm{m}^{3}$ and the thickness of the board is $0.03 \mathrm{~m}$. The motion response of the polystyrene board was analyzed with the size of the board being $1.5 \times 1.23 \mathrm{~m}$. The physical parameters of the floating polystyrene board are summarized in Table 2. According to the developed kinematic equation for the floating polystyrene board, the force acting on the board was calculated. The force on the board was related to the drift of the floating body, the mass, the damping characteristics, and the wind speed.

According to the above analysis, the kinematic equation of the heave and pitch of the floating body can be obtained. The calculation result is shown as follows:

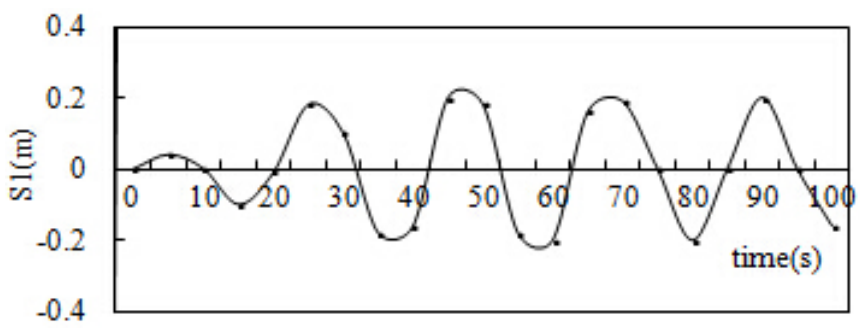

Fig. (4). Time evolution of the heave motion response.

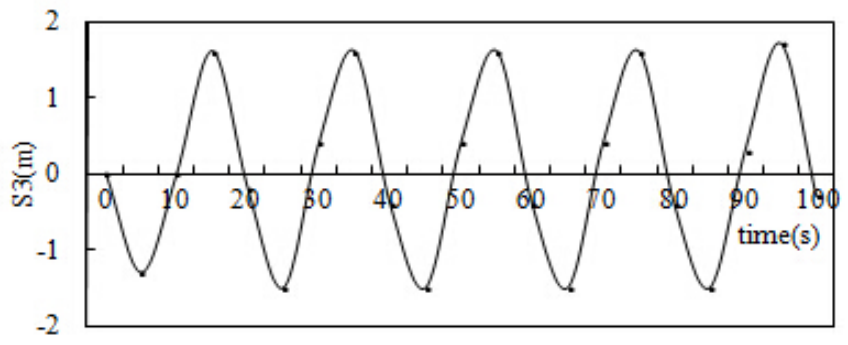

Fig. (5). Time evolution of the pitch motion response.

The above analysis shows that the calculated wave height $H=0.31 \mathrm{~m}$ and wave period $T=2.43$ with the level- 6 wind waves, where the floating board structure was tested. The maximum wave force on the floating polystyrene board $F_{\max }=11.53 \mathrm{~N}$. The calculated maximum value of the momentum $M(X)_{\max }=12.34 \mathrm{~N} \cdot \mathrm{m}$. The maximum stress to the floating board $\sigma_{\max }=80.23 \mathrm{kPa}$. The result indicated that the polystyrene board coverage structure was stable in level 6 wind-wave conditions. In the time shown in Figs. $(4,5)$, the motion of the polystyrene board coverage structure was periodic and the structure remained stable.

\section{CONCLUSION}

According to the experiment and demonstrative study over two years, the application of the polystyrene board coverage technique inhibits the annual evaporation rate by $30-50 \%$. This indicates that the polystyrene board coverage technique could save evaporation in a plain reservoir by a

Table 2. Basic parameters of floating polystyrene board.

\begin{tabular}{|c|c|c|c|c|}
\hline Items & Apparent Density /kg/m3 & Compressive Strength $/ \mathbf{k P a}$ & Heat Conductivity /w/(m· k) & Bending Strength / kPa \\
\hline \hline Parameter & 20.8 & 135 & 0.031 & 185 \\
\hline
\end{tabular}


factor of $1 / 3$, a significant resource in an area of water shortage such as Xinjiang. The biggest challenge is to overcome damaging effects of wind waves, which are also the biggest barriers to the promotion of the application of this technique.

Through long-term observation, it was found that coverage of the reservoir by a polystyrene board could effectively lessen the effect of wind speed on the water surface. In addition, the insulation effect of the board could decrease the water temperature. All these factors resulted in significant inhibition of evaporation on the water surface. The demonstrative study of the polystyrene board coverage aimed to discuss the promotion of the application in plain reservoirs. According to the current study, the appropriate polystyrene board connection and fix strategy resists the damage of wind waves, serving the purpose of inhibition of the evaporation.

Under the wind effect on the reservoir, a series of waves with different wavelengths and wave speeds were formed on the water surface. They interfered and overlapped at different directions, making them irregular and chaotic. This type of irregular wave had a very different wave height and strong randomness, so that the waveform could not be described as a function. To simplify the analysis and calculation, the motion response of the floating polystyrene board was only considered in regular waves. The result showed that the heave and pitch responses of the floating board were periodic, consistent with the observation result. The motion response in irregular waves is subject to further investigation.

\section{CONFLICT OF INTEREST}

The authors confirm that this article content has no conflict of interest.

\section{ACKNOWLEDGMENTS}

This work was financially supported by "The $12^{\text {th }}$ FiveYear" National Science and Technology Support Plan
Program of China (Grant No. 2013BAC10B01) and Project supported by the Joint Funds of the National Natural Science Foundation of China (Grant No. U1203282).

\section{REFERENCES}

[1] Wei-Zhong HU. Discussing water rational development and utilization of water resources and water environmental protection in Xinjiang. Environ Pro Xinjiang 1996; 21(2): 31-8.

[2] Liu Y, Wang LI. Study on the adoption and determinants of agricultural water saving technologies. J Natur Resour 2011; 26(6): 932-42.

[3] Pu-te W, Feng H, Niu WQ. Analysis of developmental tendency of water distribution and water-saving strategies. Trans Case 2003; 19(1):1-6.

[4] Wang J. The effect of hydrophyte for water surface temperature and evaporation. Arid Ageogeraph 1994; 17(2): 67-9.

[5] Kebin S. On Water conservation by reservoir in XinJiang. Mech Engineer 2002; 24(6): 128-35.

[6] Yan XJ. Study on water saving by preventing evaporation experiment in inland arid area plain reservoirs. J Xinjiang Agr Univ 2004; 5(2): 12-9.

[7] Yan X, Shi K, Zhuge W. Preliminary experimental study on water saving by preventing evaporation in arid area plain reservoirs. Xinjiang Agr Sci 2004; 41(4): 228-32.

[8] Korvinkroukovsky BV. Investigation of ship motions in regular waves. Trans Snam 1955; 19(5): 63-6.

[9] Tasa I. On the swaying yawing and rolling motions of ships in oblique waves. Int Build Prog 1967; 4(153): 19-67.

[10] Salvesenn T, Faltinseno EO. Ship motions and sea loads. Trans Sname 1970; 78(15): 250-87.

[11] Yan XJ, Shi KB, Zhuge WS. Preliminary experimental study on water saving by preventing evaporation in arid area plain reservoirs. Xinjiang Agric Sci 2004; 41(4): 228-32.

[12] Wu JH. Experimental study on inhibiting water surface evaporation of reservoir on arid region. Xi'An: Xi'An University of Technology 2008.

[13] Korvinkroukovsky BV. Investigation of ship motions in regular waves]. Trans SNAME 1955; pp. 63-66.

[14] Tasa I. On the swaying yawing and rolling motions of ships in oblique waves. International Ship building Progress 1967; 14: 153.

[15] Salvesenn T, Faltinsen O. Ship motions and sea loads. Trans SNAME 1970; 78: pp. 250-287.

[16] You X-C. Computational analysis on high-order waves and wave loads. Dalian: Dalian University of Technology 2005.

Received: May 26, 2014

Revised: July 14, 2014

Accepted: August 10, 2014

(C) Jiang and Tian; Licensee Bentham Open.

This is an open access article licensed under the terms of the Creative Commons Attribution Non-Commercial License (http://creativecommons.org/licenses/ by-nc/4.0/) which permits unrestricted, non-commercial use, distribution and reproduction in any medium, provided the work is properly cited. 